\title{
Imaging modalities of submandibular sialadenitis secondary to submandibular sialolithiasis: A case report
}

\author{
Rashmi Sane $^{1}$, Vikrant Sane ${ }^{2, *}$, Seema Patil ${ }^{3}$, Vaishali Koranne ${ }^{4}$ \\ 1,3,4 Assistant Professor, ${ }^{2}$ Associate Professor, ${ }^{\mathbf{1 , 4}}$ Dept. of Oral Medicine, Diagnosis and Radiology, ${ }^{2}$ Dept. of Oral \& Maxillofacial \\ Surgery, ${ }^{3}$ Dept. of Prosthodontics, Bharati Vidyapeeth (Deemed to be) University Dental College and Hospital, Pune, \\ Maharashtra, India
}

*Corresponding Author: Vikrant Sane

Email: vikrantsane@gmail.com

\begin{abstract}
Sialoliths are calcified organic matter that is formed within the secretory system of the major salivary glands which commonly affects the submandibular gland or its duct and frequently causes acute and chronic infections. In recent years, advanced imaging techniques have improved the sensitivity of imaging diagnosis of diseases involving the major salivary glands. Various imaging methods like plain radiography, sialography, Ultrasound (US), Magnetic Resonance Imaging (MRI), Computed Tomography (CT), Cone Beam Computed Tomography (CBCT) and nuclear scintigraphy/Positron Emission Tomography (PET) play a important role in diagnosis and planning the management, operative or otherwise. This article reviews a case report of a patient presenting with Sialolithiasis of right Wharton's duct with secondary acute bacterial sialadenitis in right submandibular salivary gland and methods used for imaging.
\end{abstract}

Keywords: Computed tomography, Sialadenitis, Sialolith, Submandibular gland.

\section{Introduction}

"Lithiasis" is a term used to describe a calcified mass which occurs within the ducts or parenchyma of the glandular structures and "Sialolithiasis" is a pathological condition in which calcified stones (sialoliths) occur within the salivary gland or its duct. Sialolithiasis accounts for more than 50\% of diseases affecting the major salivary glands and therefore is the most common cause of acute and chronic infections. ${ }^{1}$ Sialoliths commonly occur in the glandular parenchyma or in the salivary duct system which cause obstruction of the salivary flow resulting in periodic episodes of localized pain and swelling particularly during meals. The most common site is submandibular gland (in $80 \%$ of cases), followed by the parotid gland (in $10 \%$ of cases), and the sublingual gland (in 3\% of cases). ${ }^{2}$ Sialolith is mainly formed by layered deposition of mineral substances around the nidus and is composed of desquamated cells, necrotic debris or foreign bodies. Sialolith varies in shape from round to oval or they are elongated with irregular, knobby or granular surface area. ${ }^{3}$ Sialolith is a mixture which mainly consists of calcium phosphate and carbonates in the form of hydroxyapatite and small amounts of ammonia, magnesium and potassium. ${ }^{4}$ The submandibular gland is the most common site for a sialolith because of its anatomical variations like long and tortuous trajectory of the duct, force of gravity and the mucous secretion that is produced by the glands. ${ }^{5}$ Here we present a case of Sialolithiasis of right Wharton's duct with secondary acute bacterial sialadenitis in right submandibular salivary gland and various methods used for imaging.

\section{Case Report}

A 38 year old female visited the department of oral medicine and radiology with a chief complaint of pain and swelling on the lower right side of the neck since 56 days (Fig. 1,2,3). The swelling gradually increased in size over a period of 5-6 days and as attained the present size. The patient also gave history of increase in swelling and severe pain while eating meals which relieved on intake of warm salt water. The patient gives history of mild fever which subsided after medications prescribed by a physician, Tab Novoclox $500 \mathrm{mg}$ and Tab Enzoflam for 5 days. She had temporary relief after taking medications. Her medical history and habit history was non-relevant. Extra oral examination showed a solitary diffuse swelling measuring approximately $4 \times 2 \mathrm{~cm}$ in the right submandibular region which was soft to firm in consistency and tender on palpation. The skin over the swelling was normal. Intraoral examination showed pit and fissure caries with 18,28 . The floor of the mouth revealed a solitary oval swelling on right side of floor of mouth in realtion to 47, 48 measuring approximately $2.5 \times 1.2 \mathrm{~cm}$ with erythematous overlying mucosa and pus discharge from opening of the Wharton's duct. The swelling was hard in consistency tender on palpation and there was pus discharge after milking the gland (Fig. 4). Provisional diagnosis of Sialolith in right submandibular duct with resultant acute bacterial sialadenitis was made. Occlusal view showed no abnormal findings, lateral oblique view of right ramus was made which revealed a well defined radiopacity at the apex of distal root of 48, measuring approximately $0.5 \times 0.5 \mathrm{~cm}$ (Fig. 5). Ultrasonography and CT scan was performed. Ultrasonography report was suggestive of $7 \mathrm{~mm}$ sialolith in submandibular duct at the margin of the gland with mild proximal dilatation 
with a collection measuring $24 \times 16 \mathrm{~mm}$ around the calculus. Computed tomography showed evidence of $7.5 \mathrm{~mm}$ well defined radio dense lesion in the proximal part of right Wharton's duct (Fig. 6,7,8). The overall impression was suggestive of Sialolithiasis of the right Wharton's duct.
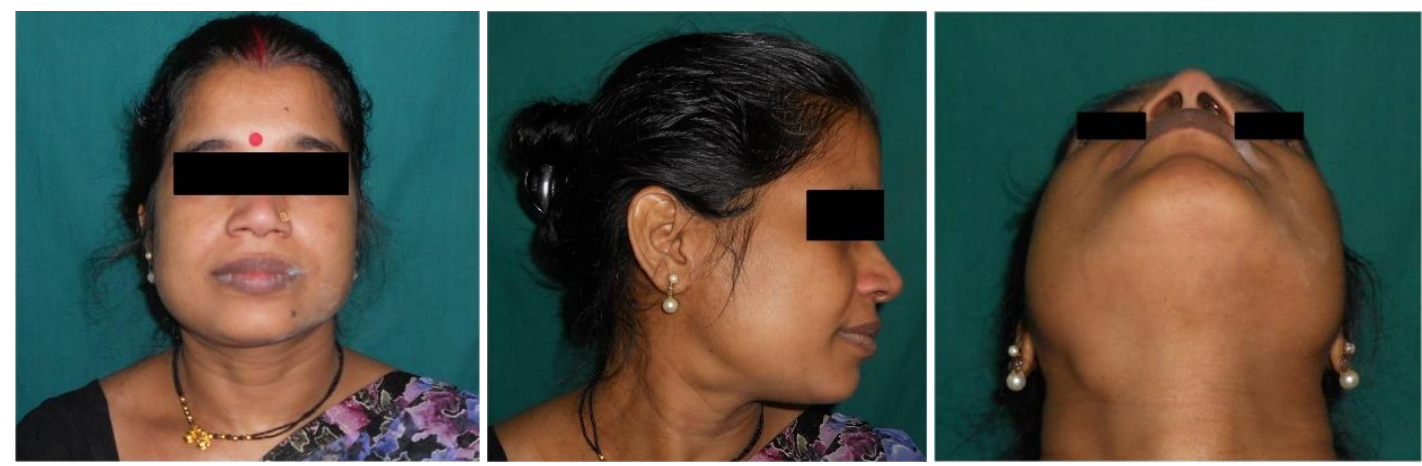

Fig. 1,2,3: Swelling on the lower right side of the neck.

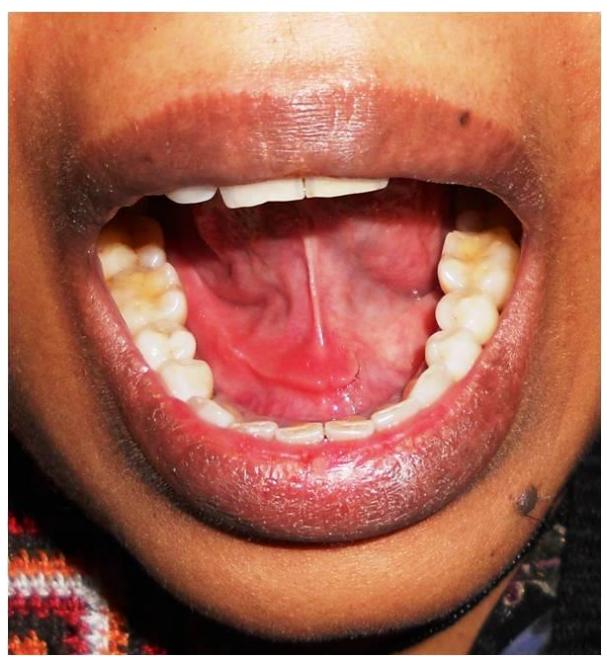

Fig. 4: Inflammation of right wharton's duct with erythematous overlying mucosa

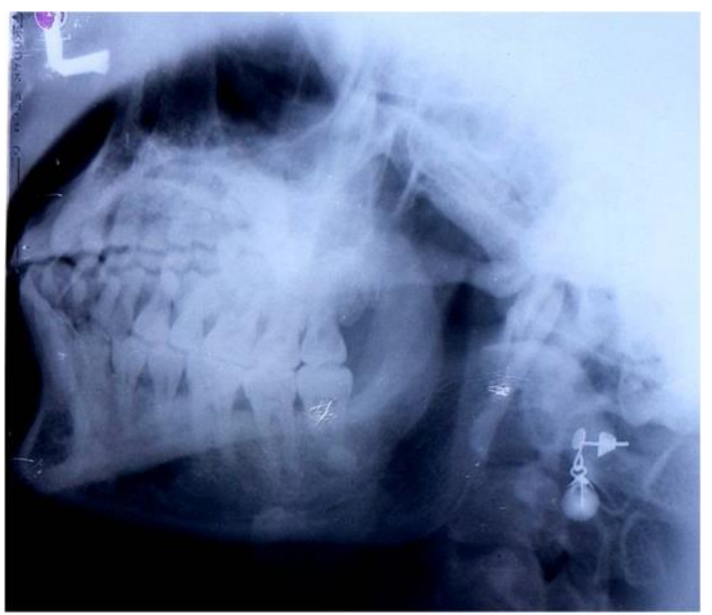

Fig. 5: lateral oblique view of right ramus was made which revealed a well defined radiopacity at the apex of distal root of 48 , measuring approximately $0.5 \times 0.5 \mathrm{~cm}$
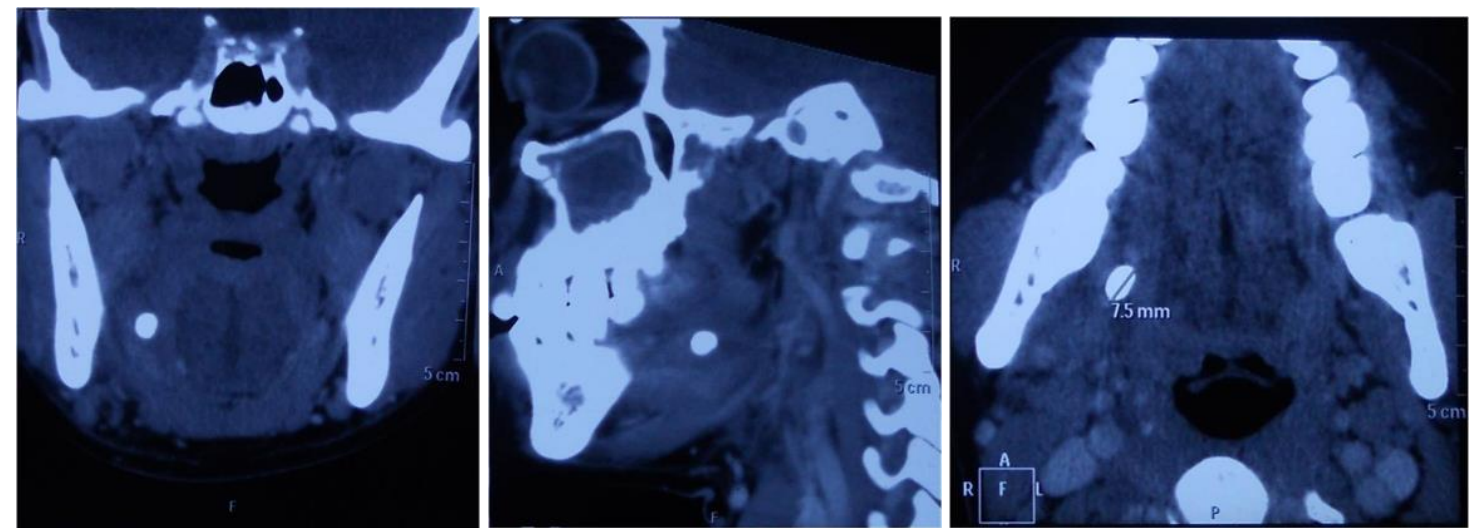

Fig. 6,7,8: Computed tomography showed evidence of $7.5 \mathrm{~mm}$ well defined dense lesion in the proximal part of right Wharton's duct

\section{Discussion}

Sialolithiasis is considered the most common disease of salivary glands affecting 12 in 1000 of the adult population. ${ }^{6}$ Males are commonly affected than females. ${ }^{7}$ In our case report a 38 year old female was affected which is not consistent with the literature. 
According to the literature, the etiology of formation of a sialolith is not known but it is said to occur in two phases: 1.) A central core and 2.) A layered periphery. The precipitation of salts bounded by few organic substances form the central core and layered deposition of organic and inorganic material forms the second phase. ${ }^{8}$ Almost $80 \%$ of the calculi form in the submandibular gland consisting of inorganic material which is $82 \%$ and organic material which is $18 \%$, followed by parotid gland which consists of $49 \%$ inorganic and $51 \%$ organic material. ${ }^{9}{ }^{10}$ In our case, the site of the sialolith was the submandibular gland which is consisitent with the literature.

Sialolithiasis are mainly diagnosed depending on the clinical presentation and the symptoms of the patient which are intermittent swelling and pain during meals which is due to increase in the intraglandular pressure, therefore called as "mealtime syndrome". ${ }^{11}$ In our case, the patient complained of increase in swelling and pain during meals which is consistent with literature.

Imaging of salivary gland is very important as it is helpful in detecting the site, nature and extension of lesion, evaluating the ductal morphology, selecting site of biopsy and planning treatment. It helps in differentiating between diffuse and focal suppurative lesions. Depending on pathology and patient factors selection of imaging modality should be done. ${ }^{12}$ In our case, mandibular occlusal radiograph, Lateral oblique view, Ultrasonography and CT scan was done. Mandibular occlusal radiograph did not show any abnormality. Lateral oblique view radiograph showed a well defined radiopacity at the apex of distal root of 48 , measuring approximately $0.5 \quad \mathrm{x} \quad 0.5 \quad \mathrm{~cm}$. Ultrasonography report was suggestive of $7 \mathrm{~mm}$ sialolith in submandibular duct. CT scan was performed to confirm the exact location of the sialolith. Clinical findings of sialadenitis are enlarged, tender submandibular gland and pus discharge from the duct are suggestive. CT scan was very helpful in localizing the sialolith and confirming its effect on the gland.

$35 \%$ of calculi mainly form in the proximal segment of the Wharton's duct which is a steep angle where the duct wraps around the posterior edge of the mylohyoid muscle whereas $30 \%$ of the calculi are located near the opening and $20 \%$ in the medial part of submandibular duct. ${ }^{13}$ In our case, Computed tomography showed a $7.5 \mathrm{~mm}$ well defined dense lesion in the proximal part of right Wharton's duct which was consistent with literature.

Various treatment options are available which mainly depend on the size and location of the sialolith. Bimanual palpation if frequently done for small stones which are "milked out" through the duct. Surgical removal or shock wave lithotripsy is recommended for larger stones spotted in the proximal segment of duct. Sialoendoscopy is a minimally invasive method for treating large salivary stones. ${ }^{14}$

\section{Conclusion}

Several imaging modalities can be utilized in the diagnosis of sialolithiasis depending on patient's symptoms. Imaging modalities play a significant role in the diagnosis and localization of sialoliths and affect the outcome of their management.

\section{References}

1. Vimal Kalia, Geeta Kalra, Supreet Kaur, Rajeev Kapoor. CT Scan as an Essential Tool in Diagnosis of Nonradiopaque Sialoliths. J Maxillofac Oral Surg. 2015;14(1):S240-S244.

2. Ricardo Martins, Carlos Augusto Ferreira Alves, Edson Martins de Oliveira Junior, Fernando Melhem Elias, Antônio Carlos de Campos. Intra-oral surgical access for the treatment of bilateral submandibular sialolithiasis: case report. Autopsy and Case Reports. 2012;2(2):37-41.

3. Lustmann J, Shteyer A. Salivary calculi: ultrastructural morphology and bacterial etiology. J Dent Res. 1981;60:1386.

4. Williams MF. Sialolithisis Otolaryngol Clin North Am. 1999;32:819-834.

5. Ellis III E, Hupp JR, Tucker MR. Cirurgia oral e maxilofacial contemporânea. 5. ed. Rio de Janeiro: Elsevier; 2009.

6. Marchal F, Kurt AM, Dulguerov P, Lehmann W.Retrograde theory in sialolithiasis formation. Arch Otolaryngol Head Neck Surg. 2001;127(1):66-8.

7. Rauch S, Gorlin R J. Disease of the salivary glands. In: Thomas' Oral Pathology. Gorlin RJ, Goldmann HM (Eds.), Mosby-Year Book Inc: St Loius, Mo. 1970:p9971003.

8. PE Chandra Mouli, S Manoj Kumar, S Kailasam, S Shanmugam, S Satish. Sialolith. A Case Report with Review of Literature. Indian Journal of Multidisciplinary Dentistry, Vol. 2, Issue 1, November 2011 to January 2012.

9. Zenk J, Benzel W, Iro H. New modalities in the management of human sialolithiasis. Minimal Invas Ther Allied Technol. 1994;3(5):275-84.

10. Iwona Rzymska-Grala, Zygmunt Stopa, Bartłomiej Grala, Marek Gołębiowski, Hubert Wanyura, Anna Zuchowska, Monika Sawicka, Michał Zmorzyński. Salivary gland calculi - contemporary methods of imaging. Pol J Radiol. 2010;75(3):25-37.

11. S.R Ashwini Rani. Suragimath G, Bijjaragi S, Shetty P. K, Mealtime syndrome: An Enigma to Resolve. $J A d v$ Med Dent Science. 2014; 2(1):120-23.

12. Bhaumik Joshi. Imaging the Major Salivary Glands: A Review. Adv Dent \& Oral Health 2018;8(4):00-003.

13. Madani G, Beale T: Inflammatory Conditions of the Salivary Glands. Semin Ultrasound CT MRI. 2006;27(6): 440-51

14. Bodner L. Giant salivary duct calculi: Diagnostic imaging \& surgical management. OOOE. 2002;94:320 